\title{
Expression of lipid metabolism genes provides new insights into intramuscular fat deposition in Laiwu pigs
}

\author{
Hui Wang ${ }^{1, a}$, Jin Wang ${ }^{1, a}$, Dan-dan Yang ${ }^{1}$, Zong-li Liu ${ }^{1}$, Yong-qing Zeng ${ }^{1, *}$, and Wei Chen ${ }^{1, *}$
}

\author{
* Corresponding Authors: \\ Yong-qing Zeng \\ Tel: +86-538-8242478, Fax: +86-538-8241419, \\ E-mail: yqzeng@sdau.edu.cn \\ Wei Chen \\ Tel: +86-538-8242478, Fax: +86-538-8241419 \\ E-mail: wchen@sdau.edu.cn
}

'Shandong Provincial Key Laboratory of Animal Biotechnology and Disease Control and Prevention, College of Animal Science and Technology, Shandong Agricultural University, Tai'an, Shandong 271000 , China

a These authors contributed equally to this work.

ORCID

Hui Wang

https://orcid.org/0000-0002-2294-1085 Jin Wang

https://orcid.org/0000-0001-6974-4970

Dan-dan Yang

https://orcid.org/0000-0002-2694-3256

Zong-li Liu

https://orcid.org/0000-0003-0607-9285

Yong-qing Zeng

https://orcid.org/0000-0002-0740-2470

Wei Chen

https://orcid.org/0000-0002-2901-5156

Submitted Mar 16, 2018; Revised Jul 23, 2018 Accepted Jun 11, 2019
Objective: The objective of this study was to measure the special expression pattern of lipid metabolism genes and investigate the molecular mechanisms underlying intramuscular fat (IMF) deposition in Longissimus dorsi muscle of Laiwu pigs.

Methods: Thirty-six pigs (Laiwu $\mathrm{n}=18$; Duroc $\times$ Landrace $\times$ Yorkshire $\mathrm{n}=18$ ) were used for the measurement of the backfat thickness, marbling score, IMF content, and expression of lipid metabolism genes.

Results: Significant correlations were found between IMF content and the mRNA expression of lipid metabolism genes. Of the 14 fat deposition genes measured, fatty acid synthase (FASN) showed the strongest correlation $(\mathrm{r}=0.75, \mathrm{p}=0.001)$ with IMF content, and of the 6 fat removal genes, carnitine palmitoyl transferase $1 \mathrm{~B}(C P T 1 B)$ exhibited the greatest negative correlation $(\mathrm{r}=-0.66, \mathrm{p}=0.003)$ with IMF content in Laiwu pig. Multiple regression analysis showed that CPT1B, FASN, solute carrier family 27 member 1 (SLC27A1), and fatty acid binding protein 3 (FABP3) contributed $38 \%$ of the prediction value for IMF content in Laiwu pigs. Of these four variables, $C P T 1 B$ had the greatest contribution to IMF content (14\%) followed by FASN (11\%), SLC27A1 (9\%), and FABP3 (4\%).

Conclusion: Our results indicate that the combined effects of an upregulation in fat deposition genes and downregulation in fat removal genes promotes IMF deposition in Laiwu pigs.

Keywords: Gene Expression; Intramuscular Fat; Laiwu Pig; Lipid Metabolism; Longissimus dorsi Muscle

\section{INTRODUCTION}

Porcine intramuscular fat (IMF) and backfat thickness are essential determinants of fresh meat quality in pig production. It is widely accepted that a higher IMF content has a positive effect on the sensory experience associated with eating better quality meat [1]. The IMF content is typically higher in Chinese indigenous pig breeds than in Western pig breeds and commercial pigs. The Laiwu pig is a Chinese indigenous black pig breed that exhibits excellent meat quality with a particularly high IMF content $[2,3]$.

The IMF is influenced by genetic and other factors, such as age, gender, and nutrition; however, genetic determinants offer the best platform for determining the molecular mechanisms of IMF deposition. Thus, genetic and genomic approaches have been used to identify quantitative trait loci and to evaluate potential candidate genes for IMF deposition in pigs $[4,5]$. These studies have identified many candidate genes, including some that can be used as biomarkers for the IMF trait [6,7].

The combined effects of lipid metabolism genes on IMF deposition have not yet been reported for the Laiwu pig. The objectives of this research were to measure the expression pattern of lipid metabolism genes in the Longissimus dorsi (LD) muscle of Laiwu pigs, and 
to use this information to elucidate the molecular mechanisms underlying IMF deposition in this breed.

\section{MATERIALS AND METHODS}

This work was approved by the Institutional Animal Care and Use Ethics Committee of Shandong Agricultural University and carried out in accordance with the "Guidelines for Experimental Animals" of the Ministry of Science and Technology (Beijing, PR China).

Animals, sample collection and lipid metabolism genes A total of 36 castrated boars (18 Laiwu pigs and 18 Durocx Landrace $\times$ Yorkshire [DLY] pigs) were selected and managed in two groups at a Laiwu pig breeding farm, and fed the same commercial fattening diet and water was provided ad libitum. The pigs were handled according to the "Regulations on Administration of Hog Slaughter" and "Good manufacturing practice for pig slaughter (GB/T 19479-2004)" of China and slaughtered following standard industry procedures. The initial body weight of the pigs was $30 \mathrm{~kg}$. When the average live weight of the pigs was $80 \pm 5 \mathrm{~kg}$, the pigs were slaughtered at a local commercial abattoir following standard industry procedures. Immediately after slaughter, two samples of $\mathrm{LD}$ muscle from the left side of the last rib of each pig were collected. One sample was frozen in liquid nitrogen and stored at $-80^{\circ} \mathrm{C}$ for gene expression analysis, and another was stored at $4^{\circ} \mathrm{C}$ for analysis of IMF content.

The average backfat thickness of each carcass was measured according to the "Technical regulation for testing of carcass traits in lean-type pig (NY/T 825-2004)" of China. Briefly, the backfat thickness at the first rib, last rib and last lumbar vertebra was measured by vernier caliper, and then the average value of the three local was the average backfat thickness. Based on the "Technical regulation for determination of pork quality (NY/T 821-2004)", marbling scores were evaluated by trained university personnel according to the National Pork Producers Council (1994), and IMF content was evaluated according to the Soxhlet petroleum-ether extraction method. IMF content is expressed as the weight percentage of wet muscle tissue.

Lipid metabolism genes selection, RNA extraction and quantitative real-time polymerase chain reaction

Thirty lipid metabolism genes were chosen from previous studies on pigs and other animals (Table 1) for their involvement in lipogenesis, fat uptake, fatty acid esterification, lipolysis, or fatty acid oxidation. Adipocytokine and transcription factors were also considered as key molecules in the regulation of adipogenesis.

Total RNA was extracted using Trizol reagent (Invitrogen, Carlsbad, CA, USA) according to the manufacturer's protocol.
This total RNA was quantified by measuring the optical density at $260 \mathrm{~nm}$, and its integrity was evaluated by $1 \%$ agarose gel electrophoresis. Ratios of absorption $(260 / 280 \mathrm{~nm})$ of all preparations were between 1.8 and 2.0. Total RNA was then reverse transcribed to cDNA using a PrimeScript RT reagent kit with gDNA Eraser (TaKaRa, Dalian, China) according to the manufacturer's instructions.

Real-time polymerase chain reaction (PCR) was performed using SYBR Premix Ex Taq (Takara, China) and an Mx3000P Real-Time PCR System (Stratagene, La Jolla, CA, USA). Amplifications were performed in a $25 \mu \mathrm{L}$ reaction volume containing $12.5 \mu \mathrm{L}$ of $2 \times$ SYBR Premix ExTaq, $0.5 \mu \mathrm{L}$ of each primer, $2 \mu \mathrm{L}$ of diluted cDNA, $0.5 \mu \mathrm{L}$ of ROX Reference Dye II, and sterile water. The PCR amplification was carried out as follows: $95^{\circ} \mathrm{C}$ for $10 \mathrm{~s}$, then 40 cycles of $95^{\circ} \mathrm{C}$ for $5 \mathrm{~s}$ and $58^{\circ} \mathrm{C}$ for $10 \mathrm{~s}$ and $72^{\circ} \mathrm{C}$ for $15 \mathrm{~s}$, followed by $1 \mathrm{cycle}$ of $95^{\circ} \mathrm{C}$ for $1 \mathrm{~min}, 61^{\circ} \mathrm{C}$ for $30 \mathrm{~s}$, and $95^{\circ} \mathrm{C}$ for $30 \mathrm{~s}$ to calculate the melting curve. To exclude between-run variation, all samples were amplified in triplicates and the mean was used for further analysis. Primer sets used are listed in Supplemental Table S1.

Beta-2 microglobulin, eukaryotic translation elongation factor 1 alpha 1 (EEF1A1), glyceraldehyde-3-phosphate dehydrogenase, peptidylprolyl isomerase A (PPIA), and TATA box-binding protein were amplified as endogenous control genes. The stability of the candidate reference genes was evaluated with geNorm (v3.5) [8]. The most stably expressed reference genes and their optimal number for normalization were determined. Standard curves were generated using pooled cDNA from the samples being assayed, and the $\Delta \mathrm{Cq}$ method was used to quantify the mRNA expression levels of lipid metabolism genes.

\section{Statistical analysis}

The means procedure was used to calculate the mean and standard deviation values for the measured parameters (SAS Institute, v8.2, Inc., Cary, NC, USA). One-way analysis of variance followed by $t$-test were used to compare data between the two pig groups. Pearson's correlation coefficients between carcass characteristics or lipid metabolism gene expression in LD muscle and IMF content were calculated using the CORR procedure. Principal component (PC) analysis was performed to analyze the correlations of all variables (transcription of 30 genes). Stepwise regression of SAS was used to develop equations predicting IMF content using mRNA abundance of lipid metabolism genes in LD muscle. The IMF content was the dependent variable and mRNA abundance of the 30 lipid metabolism genes was the independent variables. Data in the tables and text are presented as mean \pm standard error of the mean. 
Table 1. Information of lipid metabolism related genes

\begin{tabular}{|c|c|c|c|}
\hline Gene name & Gene symbol & SSC & GenBank ID \\
\hline Acetyl-CoA carboxylase alpha & $A C A C A$ & 12 & NM_001114269 \\
\hline Acyl-CoA oxidase 1 & ACOX1 & 12 & NM_001101028 \\
\hline Acyl-CoA synthetase long-chain family member 3 & ACSL3 & 15 & NM_001143698 \\
\hline Acyl-CoA synthetase short-chain family member 2 & ACSS2 & 17 & NM_001143695 \\
\hline Adiponectin & ADIPOQ & 13 & NM_214370 \\
\hline Adiponectin receptor 1 & ADIPOR1 & 10 & NM_001007193 \\
\hline 1-acylglycerol-3-phosphate 0-acyltransferase 1 & AGPAT1 & 7 & NM_001033008 \\
\hline CCAAT/enhancer binding proteins (C/EBP), alpha & CEBPA & 6 & AF103944 \\
\hline CCAAT/enhancer binding proteins (C/EBP), beta & CEBPB & 17 & NM_001199889 \\
\hline Catalase & CAT & 2 & NM_214301 \\
\hline CD36 molecule (thrombospondin receptor) & CD36 & 9 & NM_001044622 \\
\hline Carnitine palmitoyl transferase 1B (muscle) & CPT1B & - & NM_001007191 \\
\hline Diacylglycerol acyltransferase 1 & DGAT1 & 4 & NM_214051 \\
\hline Diacylglycerol acyltransferase 2 & DGAT2 & 9 & NM_001160080 \\
\hline Fatty acid binding protein 3 , muscle and heart & FABP3 (H-FABP) & 6 & NM_001099931 \\
\hline Fatty acid binding protein 4, adipocyte & FABP4 (A-FABP) & - & NM_001002817 \\
\hline Fatty acid synthase & FASN & 12 & NM_001099930 \\
\hline Leptin & $L E P$ & 18 & NM_213840 \\
\hline Leptin receptor & $L E P R$ & 6 & NM_001024587 \\
\hline Lipase, hormone-sensitive & LIPE (HSL) & 6 & NM_214315 \\
\hline Lipoprotein lipase & $L P L$ & - & NM_214286 \\
\hline Monoglyceride lipase & MGLL & 13 & NM_001143718 \\
\hline Patatin-like phospholipase domain containing 2 & PNPLA2 (ATGL) & 2 & NM_001098605 \\
\hline Peroxisome proliferator-activated receptor alpha & PPARA & 5 & NM_001044526 \\
\hline Peroxisome proliferator-activated receptor gamma & PPARG & 13 & NM_214379 \\
\hline Retinoid $X$ receptor gamma & $R X R G$ & 4 & NM_001130213 \\
\hline Stearoyl-coenzyme A desaturase & $S C D$ & 14 & NM_213781 \\
\hline Solute carrier family 27 (fatty acid transporter), member 1 & SLC27A1 (FATP1) & 2 & NM_001083931 \\
\hline Solute carrier family 2 (facilitated glucose transporter) member 4 & SLC2A4 (GLUT4) & 12 & NM_001128433 \\
\hline Sterol regulatory element binding transcription factor 1 & SREBF1 (SREBP-1C) & 12 & NM_214157 \\
\hline
\end{tabular}

SSC, Sus scrofa chromosome.

\section{RESULTS}

\section{Backfat thickness, marbling score and intramuscular fat content}

The average backfat thickness, marbling score and IMF content were significantly higher in Laiwu than DLY pigs (Figure 1). The IMF content was $9.43 \%$ and $1.64 \%$ for Laiwu and DLY pigs, respectively $(\mathrm{p}<0.05)$. Marbling score, a measure of the amount and distribution of IMF in LD muscle, was positively correlated with IMF content in Laiwu $(r=0.48, p=0.039)$ and DLY pigs $(r=0.43, p=0.046)$. Likewise, average backfat thickness was positively correlated with IMF content in Laiwu $(\mathrm{r}=0.72, \mathrm{p}=0.008)$ and DLY pig $(\mathrm{r}=0.72, \mathrm{p}=0.007)$.

\section{mRNA expression of lipid metabolism genes}

Evaluation of candidate reference genes by geNorm showed that EEF1A1 and PPIA were the most stably expressed genes. These two genes were used to normalize the expression of lipid metabolism genes. The normalized mRNA abundance of lipid metabolism genes is reported in Figure 2. The expression of acetyl-CoA carboxylase alpha ( $A C A C A)$, fatty acid synthase (FASN), solute carrier family 27 member 1 (SLC27A1), adiponectin (ADIPOQ), and 1-acylglycerol-3-phosphate Oacyltransferase 1 in muscle tissue was significantly higher in Laiwu than DLY pigs. Conversely, of the fatty acid oxidation genes, only carnitine palmitoyl transferase $1 \mathrm{~B}(C P T 1 B)$ showed a significant difference between groups, being significantly higher in DLY than Laiwu pigs $(\mathrm{p}<0.05)$. The expression of fatty acid binding protein $4, F A S N$, peroxisome proliferator-activated receptor gamma $(P P A R G)$, and $A D I P O Q$ in backfat tissue was significantly higher in Laiwu than DLY pigs ( $<<0.05$; Supplementary Figure $S 1$ ). Expression of the remaining genes showed no significant differences between Laiwu and DLY pigs.

\section{Correlations between the expression of lipid} metabolism genes and intramuscular fat content There were many significant Pearson's correlations between 

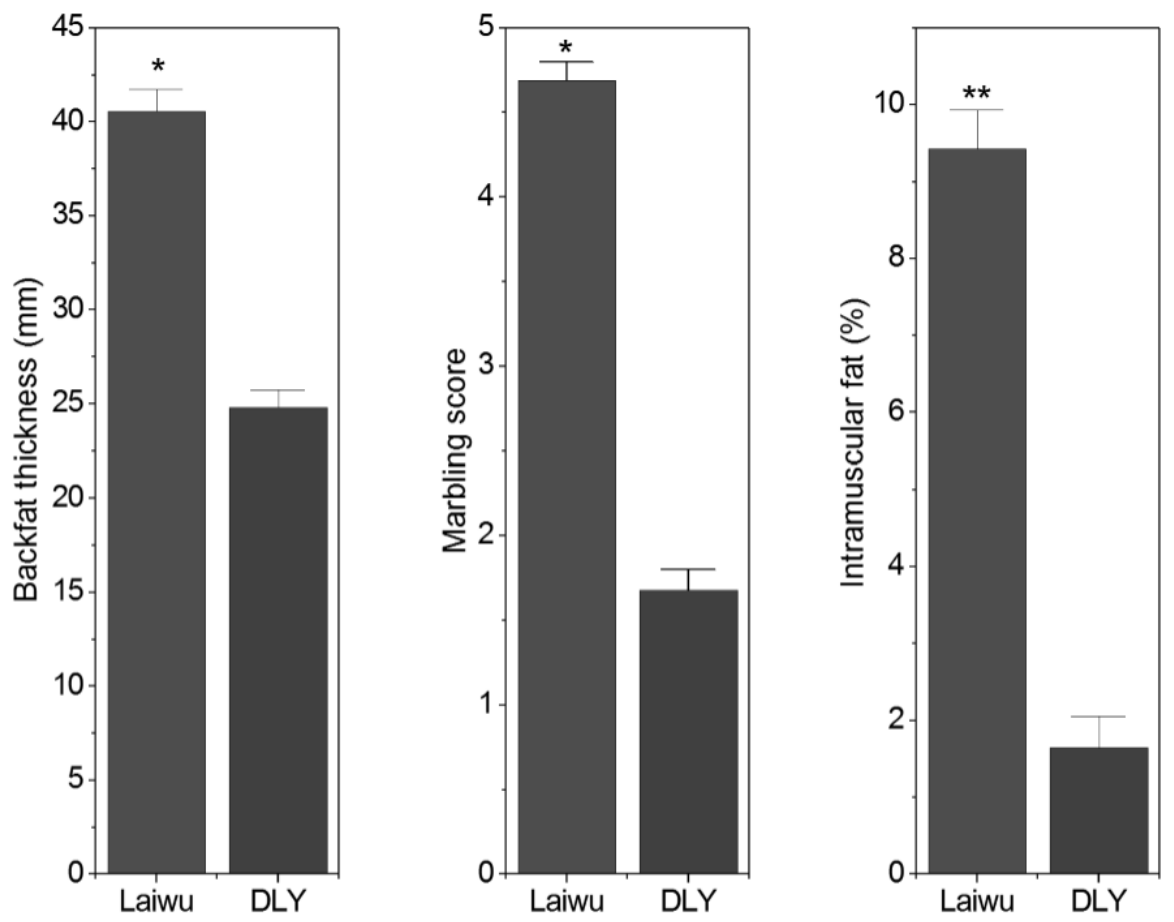

Figure 1. Average backfat thickness, marbling score and IMF content of Laiwu and DurocxLandracexYorkshire (DLY) pigs. ${ }^{*} p<0.05,{ }^{* *} p<0.01$.

IMF content and the mRNA abundance of lipid metabolism genes (Table 2). In muscle tissue of both pig groups, IMF content was positively correlated $(\mathrm{p}<0.05)$ with the expression of lipid transportation and adipocytokine genes. The IMF content was also correlated $(\mathrm{p}<0.05)$ with mRNA abundance of diacylglycerol acyltransferase 1 (DGAT1), stearoyl-coenzyme A desaturase, lipase (LIPE), CCAAT/enhancer binding proteins $(\mathrm{C} / \mathrm{EBP})$, beta $(C E B P B)$, peroxisome proliferator-activated receptor alpha (PPARA), PPARG, and sterol regulatory element binding transcription factor 1 (SREBF1). Monoglyceride lipase (MGLL) expression was negatively correlated and LIPE expression positively correlated with IMF content. In Laiwu pig, IMF content was positively correlated with lipoprotein lipase, SLC27A1, ACACA, acyl-CoA synthetase short-chain family member 2 (ACSS2), FASN, and CCAAT/enhancer binding proteins $(\mathrm{C} / \mathrm{EBP})$, alpha $(C E B P A)$ expression, and negatively correlated with patatin-like phospholipase domain containing 2 (PNPLA2), acyl-CoA oxidase 1 (ACOX1), and $C P T 1 B$ expression.

However, the mRNA abundance of ACOX1 and PPARA in backfat tissue was correlated with the IMF content in Laiwu pig, and catalase and PPARA was correlated with the IMF content in DLY pig.

\section{Principal component analysis and stepwise multiple regression analysis}

The PC analysis was used to determine whether any of the 30 genes analyzed significantly predicted IMF content in
Laiwu pigs. The PC analysis extracted two factors, PC1 and PC2, that explained $61.97 \%$ of total data variation $(43.60 \%$ and $18.37 \%$ respectively) (Figure 3). A stepwise multiple regression analysis was also performed, with four independent variables showing significant results $(p<0.05$, Table 3$)$. The total prediction value for IMF content from these variables, i.e. $C P T 1 B, F A S N$, $S L C 27 A 1$, and $F A B P 3$ expression, was $38 \%$. Of the four variables, $C P T 1 B$ represented the greatest contribution to IMF content (14\%), followed by FASN (11\%), SLC27A1 (9\%), and FABP3 (4\%). These results indicate that $C P T 1 B$ may be an important factor for predicting IMF content, and thus the decrease in fatty acid oxidation caused by reduced $C P T 1 B$ expression may be important for IMF deposition in Laiwu pigs.

\section{DISCUSSION}

Lipogenesis is the process by which acetyl coenzyme A is converted to fatty acids [9]. Ponsuksili et al [10] reported that key genes involved in lipogenesis were upregulated in the fatter German Landrace pigs. In our study, IMF content was correlated with the expression of ACACA, ACSS2, and FASN in Laiwu pigs. The most significant of these was between $F A S N$ expression and IMF content, where the mRNA abundance of FASN accounted for $11 \%$ of the variability in IMF content explained by the 30 genes analyzed. Taken together, our results suggest that the upregulation in gene expression increased the capacity for fatty acid synthesis and increased the fat ac- 


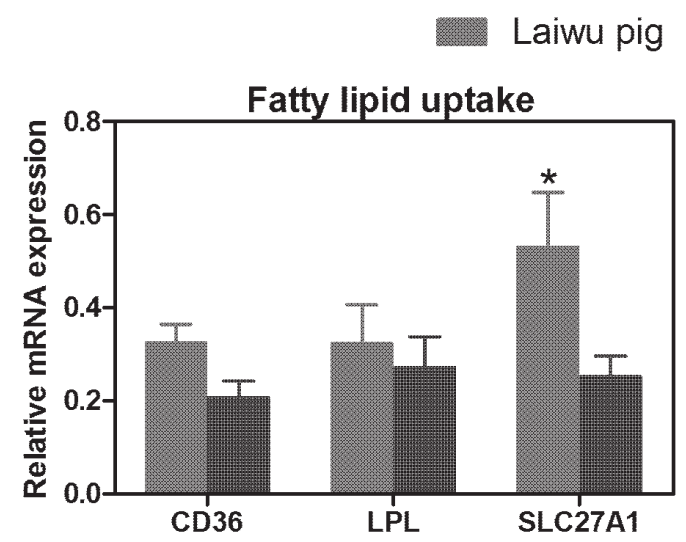

DLY pig
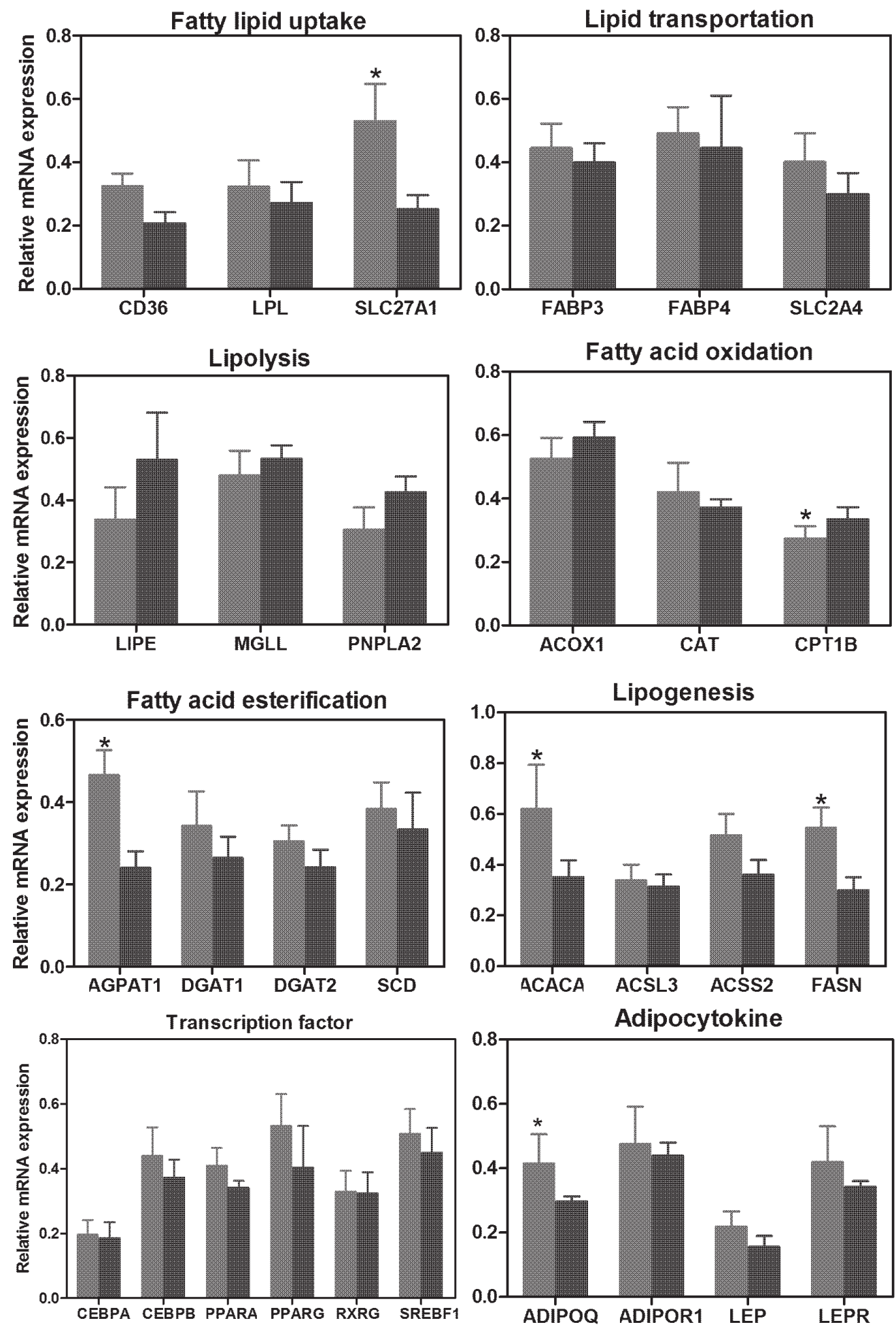

Figure 2. mRNA abundance of lipid metabolism genes in Laiwu and Duroc $x$ LandracexYorkshire (DLY) pigs. ${ }^{*} p<0.05$.

cumulation in skeletal muscle.

Previous research shows that SLC27A1 promotes longchain fatty acids uptake into differentiating adipocytes [11]. In the present study, SLC27A1 expression was correlated with
IMF content in Laiwu pigs. Importantly, the mRNA abundance of SLC27A1 accounted for 9\% of the variability in IMF content explained by the 30 candidate genes we analyzed, suggesting that increased SLC27A1 expression may promote 
Table 2. Correlation coefficients between gene expression and IMF content and backfat thickness

\begin{tabular}{|c|c|c|c|c|c|c|c|c|}
\hline \multirow{3}{*}{ Genes } & \multicolumn{4}{|c|}{ IMF content } & \multicolumn{4}{|c|}{ Backfat thickness } \\
\hline & \multicolumn{2}{|c|}{ Laiwu pig } & \multicolumn{2}{|c|}{ DLY pig } & \multicolumn{2}{|c|}{ Laiwu pig } & \multicolumn{2}{|c|}{ DLY pig } \\
\hline & $r$ & $p$ & $r$ & $p$ & $r$ & $p$ & $r$ & $p$ \\
\hline CD36 & 0.47 & 0.051 & 0.21 & 0.404 & 0.27 & 0.275 & 0.36 & 0.067 \\
\hline$L P L$ & 0.71 & 0.039 & 0.39 & 0.051 & 0.39 & 0.071 & 0.27 & 0.058 \\
\hline \multicolumn{9}{|c|}{ Lipid transportation } \\
\hline FABP3 & 0.39 & 0.003 & 0.32 & 0.025 & 0.26 & 0.098 & 0.38 & 0.117 \\
\hline FABP4 & 0.66 & 0.000 & 0.41 & 0.008 & 0.46 & 0.085 & 0.54 & 0.082 \\
\hline SLC2A4 & 0.39 & 0.046 & 0.30 & 0.023 & 0.36 & 0.147 & 0.29 & 0.053 \\
\hline \multicolumn{9}{|l|}{ Lipogenesis } \\
\hline$A C A C A$ & 0.43 & 0.015 & 0.49 & 0.171 & 0.32 & 0.200 & 0.47 & 0.054 \\
\hline AGPAT1 & 0.38 & 0.119 & 0.23 & 0.065 & 0.22 & 0.062 & 0.27 & 0.083 \\
\hline DGAT1 & 0.51 & 0.033 & 0.34 & 0.037 & 0.13 & 0.084 & 0.17 & 0.061 \\
\hline DGAT2 & 0.37 & 0.049 & 0.49 & 0.171 & 0.24 & 0.053 & 0.32 & 0.053 \\
\hline$S C D$ & 0.48 & 0.042 & 0.29 & 0.045 & 0.39 & 0.109 & 0.45 & 0.085 \\
\hline \multicolumn{9}{|l|}{ Lipolysis } \\
\hline LIPE & 0.65 & 0.003 & 0.39 & 0.011 & 0.30 & 0.224 & 0.42 & 0.082 \\
\hline MGLL & -0.61 & 0.009 & -0.33 & 0.024 & -0.62 & 0.065 & -0.57 & 0.821 \\
\hline PNPLA2 & -0.58 & 0.011 & -0.29 & 0.065 & -0.46 & 0.078 & -0.49 & 0.056 \\
\hline \multicolumn{9}{|c|}{ Fatty acid oxidation } \\
\hline ACOX1 & -0.56 & 0.015 & 0.42 & 0.085 & -0.56 & 0.016 & -0.39 & 0.071 \\
\hline \multicolumn{9}{|c|}{ Transcription factors } \\
\hline CEBPA & 0.66 & 0.003 & 0.67 & 0.068 & 0.41 & 0.087 & 0.37 & 0.052 \\
\hline CEBPB & 0.74 & 0.000 & 0.43 & 0.024 & 0.31 & 0.066 & 0.29 & 0.083 \\
\hline PPARA & 0.65 & 0.003 & 0.36 & 0.014 & 0.48 & 0.029 & 0.51 & 0.039 \\
\hline PPARG & 0.75 & 0.001 & 0.29 & 0.027 & 0.38 & 0.063 & 0.39 & 0.075 \\
\hline$R X R G$ & 0.39 & 0.112 & 0.32 & 0.065 & 0.21 & 0.218 & 0.59 & 0.175 \\
\hline SREBF1 & 0.67 & 0.002 & 0.49 & 0.038 & 0.39 & 0.065 & 0.41 & 0.052 \\
\hline
\end{tabular}

IMF, intramuscular fat; DLY, Duroc $\times$ Landrace $\times$ Yorkshire.

IMF deposition in Laiwu pigs.

Diacylgycerol acyltransferase (DGAT) catalyzes the final step in triacylglycerol biosynthesis by converting diacylgycerol and fatty acyl-coenzyme A to triacylglycerol [12]. In our study, DGAT1 and DGAT2 expression were correlated with IMF deposition in Laiwu pigs. Therefore, DGAT1 and DGAT2 may play a key role in modulating fat deposition in Laiwu pigs.

Fat removal by lipolysis is an important factor in IMF deposition in muscle in pigs. In this study, LIPE expression was positively correlated and MGLL and PNPLA2 expression negatively correlated with IMF content in Laiwu pigs. In agreement with our results, a previous study reported that $M G L L$ and PNPLA2 mRNA abundance were negatively correlated with IMF content in Korean cattle steers [13]. These results suggest that decreased lipolysis may enhance fat deposition in Laiwu pigs.

Fatty acid oxidative potential may also be important for IMF deposition in skeletal muscle in pigs. A recent study reported that decreased $C P T 1 B$ expression contributes to fat 


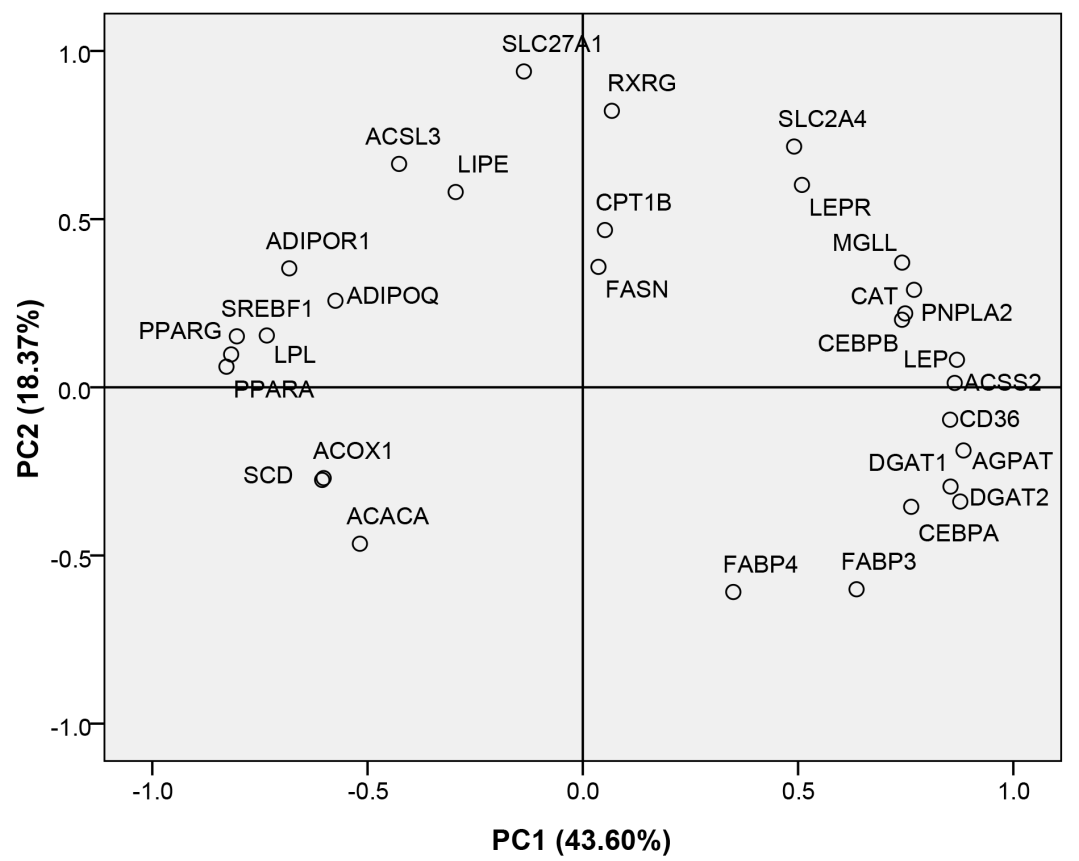

Figure 3. Variable scores for principal component (PC) 1 and 2 of the PC analysis. PC 1 and 2 explained $43.60 \%$ and $18.37 \%$ of the total variance, respectively. The PC plot representing variables in the rotated plan after PC analysis. The rotation method used was Varimax with Kaiser Normalization.

Table 3. Stepwise multiple regression analysis for predicting IMF content using the mRNA abundance of lipid metabolism genes in Laiwu pig

\begin{tabular}{lcccc}
\hline Variables & $\begin{array}{c}\text { Regression } \\
\text { coefficient }\end{array}$ & SE & Partial $\mathbf{R}^{2}$ & Pr $>\mathrm{F}$ \\
\hline Intercept & 3.19 & 0.21 & - & $<0.0001$ \\
CPT1B & -0.57 & 0.20 & 0.14 & 0.017 \\
FASN & 2.00 & 0.32 & 0.11 & 0.014 \\
SLC27A1 & 0.37 & 0.11 & 0.09 & 0.006 \\
FABP3 & 0.50 & 0.21 & 0.04 & 0.031 \\
Total R & - & - & 0.38 & - \\
\hline
\end{tabular}

IMF, intramuscular fat; SE, standard error; CPT1B, carnitine palmitoyl transferase $1 \mathrm{~B} ;$ FASN, fatty acid synthase; SLC27A1, solute carrier family 27 member 1; $F A B P 3$, fatty acid binding protein 3, muscle and heart.

accumulation in obesity [14]. In our study, CPT1B expression was negatively correlated with IMF content in Laiwu pigs, with the mRNA abundance of $C P T 1 B$ accounting for $14 \%$ of the variability in IMF content explained by the 30 genes analyzed. The $C P T 1 B$ gene may thus be used as a genetic marker for IMF deposition in Laiwu pigs, suggesting that decreased fatty acid oxidation in muscle contributes to increasing fat deposition in this breed.

ADIPOQ can inhibit the synthesis of malonyl-coenzyme A via the cell surface receptor ADIPOR1, resulting in an increase in mitochondrial import and fatty acid oxidation [15]. We found $A D I P O Q$ expression to be positively correlated with IMF content in muscle of Laiwu pigs, suggesting that ADIPOQ may promote lipid deposition in this breed.

CEBPA, CEBPB, PPARA, and PPARG expression were also correlated with IMF content in the Laiwu pigs of our study, with PPARG showing the strongest correlation with IMF content. These results indicate that an increase in $C E B P A, C E B P B$, $P P A R A$, and $P P A R G$ expression leads to enhanced lipogenesis in intramuscular adipose tissue. Moreover, SREBF1 showed a strong correlation with IMF content, suggesting that SREBF1 may be a candidate gene for determination of lipogenic capacity. Together, these results indicate that increased expression of transcription factor genes promotes fat deposition in Laiwu pigs.

\section{CONCLUSION}

The expression of most of the lipid metabolism genes selected for this study was significantly associated with IMF content, affirming the role of these genes in lipid deposition in muscle. Our results indicate that the combined effects of increases in fat deposition and decreases in fat removal contribute to increasing the IMF content, and that CPT1B, FASN, SLC27A1, and $F A B P 3$ are predictors of IMF content in the LD muscle of Laiwu pigs.

\section{CONFLICT OF INTEREST}

We certify that there is no conflict of interest with any financial organization regarding the material discussed in the manuscript. 


\section{ACKNOWLEDGMENTS}

This study was supported by the Shandong Provincial Natural Science Foundation (ZR2018BC046), the Shandong Provincial Modern Pig Technology and Industry System Project (SDAIT- 08-02), and Funds of Shandong "Double Tops" Program (SYL2017YSTD12).

\section{REFERENCES}

1. Font-i-Furnols M, Tous N, Esteve-Garcia E, Gispert M. Do all the consumers accept marbling in the same way? The relationship between eating and visual acceptability of pork with different intramuscular fat content. Meat Sci 2012;91: 448-53. https://doi.org/10.1016/j.meatsci.2012.02.030

2. Chen W, Zeng Y, Cui J, et al. Effects of phospholipid hydroperoxide glutathione peroxidase mRNA expression on meat quality of $M$. Longissimus dorsi in pigs. Eur Food Res Technol 2011;232:433-40. https://doi.org/10.1007/s00217-010-1407-3

3. Chen Q-M, Wang H, Zeng Y-Q, Chen W. Developmental changes and effect on intramuscular fat content of $H$-FABP and A-FABP mRNA expression in pigs. J Appl Genet 2013;54: 119-23. https://doi.org/10.1007/s13353-012-0122-0

4. Hamill RM, Aslan O, Mullen AM, et al. Transcriptome analysis of porcine M. semimembranosus divergent in intramuscular fat as a consequence of dietary protein restriction. BMC Genomics 2013;14:453. https://doi.org/10.1186/1471-2164$14-453$

5. Switonski M, Stachowiak M, Cieslak J, Bartz M, Grzes M. Genetics of fat tissue accumulation in pigs: a comparative approach. J Appl Genet 2010;51:153-68. https://doi.org/10. 1007/BF03195724

6. Serão NVL, Veroneze R, Ribeiro AMF, et al. Candidate gene expression and intramuscular fat content in pigs. J Anim Breed Genet 2011;128:28-34. https://doi.org/10.1111/j.14390388.2010.00887.x

7. Wang W, Xue W, Jin B, Zhang X, Ma F, Xu X. Candidate gene expression affects intramuscular fat content and fatty acid composition in pigs. J Appl Genet 2013;54:113-8. https://doi. org/10.1007/s13353-012-0131-z

8. Vandesompele J, De Preter K, Pattyn F, et al. Accurate normalization of real-time quantitative RT-PCR data by geometric averaging of multiple internal control genes. Genome Biol 2002;3:research0034.1. https://doi.org/10.1186/gb-2002-3-7research0034

9. Smith S, Witkowski A, Joshi AK. Structural and functional organization of the animal fatty acid synthase. Prog Lipid Res 2003;42:289-317. https://doi.org/10.1016/S0163-7827(02) 00067-X

10. Ponsuksili S, Murani E, Walz C, Schwerin M, Wimmers K. Pre- and postnatal hepatic gene expression profiles of two pig breeds differing in body composition: insight into pathways of metabolic regulation. Physiol Genomics 2007;29:267-79. https://doi.org/10.1152/physiolgenomics.00178.2006

11. Pohl J, Ring A, Hermann T, Stremmel W. Role of FATP in parenchymal cell fatty acid uptake. Biochim Biophys Acta Mol Cell Biol L 2004;1686:1-6. https://doi.org/10.1016/j.bbalip. 2004.06.004

12. Yen CLE, Stone SJ, Koliwad S, Harris C, Farese RV. DGAT enzymes and triacylglycerol biosynthesis. J Lipid Res 2008;49: 2283-301. https://doi.org/10.1194/jlr.R800018-JLR200

13. Jeong J, Kwon EG, Im SK, Seo KS, Baik M. Expression of fat deposition and fat removal genes is associated with intramuscular fat content in longissimus dorsi muscle of Korean cattle steers. J Anim Sci 2012;90:2044-53. https://doi.org/10.2527/ jas.2011-4753

14. Ratner C, Madsen AN, Kristensen LV, et al. Impaired oxidative capacity due to decreased CPT1b levels as a contributing factor to fat accumulation in obesity. Am J Physiol Regul Integr Comp Physiol 2015;308:R973-82. https://doi.org/10. 1152/ajpregu.00219.2014

15. Yamauchi T, Nio Y, Maki T, et al. Targeted disruption of AdipoR1 and AdipoR2 causes abrogation of adiponectin binding and metabolic actions. Nat Med 2007;13:332-9. https://doi.org/10.1038/nm1557 